\title{
Modeling of Bus Transit Driver Availability for Effective Emergency Evacuation in Disaster Relief
}

\author{
Ender Faruk Morgul, Ozlem Cavus, Kaan Ozbay, and Cem lyigun
}

Potential evacuees without access to personal automobiles are expected to use transit, especially buses, to reach safer regions. For a transit agency, operation problems to be considered include establishing bus launch areas, positioning the minimum number of required buses, and coordinating transit operators, especially determining whether the number of drivers will be sufficient to cover the number of vehicles (i.e., buses) to be used during the evacuation. It is also highly probable that during an emergency, absenteeism rates for bus drivers might increase. In this study, the authors developed two stochastic models to determine the need for extra drivers during an emergency evacuation and to provide optimal solutions using well-established concepts in mathematical programming. First, the authors reviewed the literature to develop an effective methodology for the development of optimal extraboard management strategies. The authors found that although several recent reports clearly mentioned the problem of not having enough bus drivers during emergency evacuation operations, no analytical study incorporated the optimal extraboard size problem into emergency evacuation operations. Second, two mathematical models are presented in this paper. The aim of the developed models is to fill the gap in the literature for determining optimal extraboard size for transit operations during emergency evacuations. The models are specifically designed to capture risk-averse behavior of decision makers. Finally, these models were tested with hypothetical examples from real-world data from New Jersey. Results show that both models give reasonable extraboard size estimates, and under different conditions, these models are responsive to the changes in cost and quality of service preferences. The results are encouraging in terms of the models' usefulness for real-world applications.

Transit agencies must employ enough operators for transit vehicles to meet scheduled service requirements and to account for absences because of illness, vacation, absenteeism, and the like. Agencies employ extraboard operators (on-call backups) to account for these situations and ensure that service is not interrupted. Overestimation of

E. F. Morgul and K. Ozbay, Department of Civil and Environmental Engineering, Rutgers Intelligent Transportation Systems Laboratory, Rutgers University, 96 Frelinghuysen Road, Piscataway, NJ 08854. Current affiliation for E. F. Morgul and K. Ozbay: Department of Civil and Urban Engineering, Center for Urban Science and Progress, New York University, 1 Metrotech Center, 19th Floor, Brooklyn, NY 11201. O. Cavus, Department of Industrial Engineering, Bilkent University, 06800 Ankara, Turkey. C. Iyigun, Department of Industrial Engineering, Middle East Technical University, Universiteler Mahallesi, Dumlup \#305, Nar Bulvar \#305, No. 1, 06800 Çankaya, Ankara, Turkey. Corresponding author: E. F. Morgul, efm279@nyu.edu.

Transportation Research Record: Journal of the Transportation Research Board, No. 2376, Transportation Research Board of the National Academies, Washington, D.C., 2013, pp. 45-55.

DOI: $10.3141 / 2376-06$ the number of extraboard operators comes at a significant cost. Thus efficient extraboard management is necessary for optimum use of limited resources. In the case of an evacuation, the burden on transit agencies to meet minimum service requirements (which may be greater or different from regular service) is of even higher importance. At the same time, absenteeism can be higher because of operators' personal concerns or constraints that prevent them from fulfilling their duties.

Despite its critical role in transit operations, extraboard staff allocation has not received the same level of attention in the literature as other problems, such as vehicle routing, driver cost reduction, or fleet sizing. According to the key findings of a survey of transit agencies in the United States conducted by DeAnnuntis and Morris, the majority of agencies use full-time operators as extraboard operators (hourly pay is higher than for half-time operators), the rates of absenteeism are not properly recorded or evaluated, and automated scheduling software is not used to assist in determining the extraboard requirement in lieu of historical data (1). Another study, in which decision makers from 35 transit agencies in the United States were interviewed, found that scheduling software packages used by agencies do not include a module for extraboard management. The general trend for determining the correct size of extraboard staff in practice depends on historical data and experience. The literature review conducted as part of the same study showed that the limited number of earlier efforts focused only on minimizing overtime payments. Developed models were tested for specific transit systems only, and no generic model applies to all transit systems (2).

The importance of transit-based evacuation has been increasingly recognized during the past few decades. Several studies emphasize the lack of planning to evacuate transit-based populations effectively, especially after the experiences of the terrorist attacks of September 11, 2001, in New York and Hurricanes Katrina and Rita in the southeastern United States (3-7). Performance evaluation reports after the two hurricanes clearly demonstrate a significant failure in the lack of evacuation plans for people who do not drive or are dependent on transit. Besides the lack of an effective plan, limited resources for some agencies is an obstacle. For instance, New Orleans had approximately 500 buses and needed about 2,000 buses to evacuate all of the residents who were not using their private vehicles (4). Another comprehensive analysis for transit-based emergency evacuation includes the results of a survey of agencies to evaluate the emergency plans of major urbanized areas in the country. Of 16 respondents, only one (Seattle, Washington) stated that it has a plan for ensuring that the transit staff will be available in an emergency condition, which highlights the lack of effective planning for extraboard sizing among transit agencies (3).

Extraboard management is one of the vital components of transit evacuation planning because it ensures that there will be a sufficient 
number of bus drivers to evacuate transit-dependent victims of a disaster. Thus the goal of this paper is to provide practical models that can be used to better plan to meet needs of a transit agency in terms of drivers for different types of emergency evacuations. Quality of service, which is a widely used measure of reliability, is used in these models. The objective function of the problem is to minimize the total costs of extraboard management, which include agency costs and social costs. Two models are proposed to determine the optimum number of extra drivers for a predefined quality of service requirement, which is assumed to be determined by the agency itself.

The rest of the paper is organized as follows. The next section is a review of the literature about extraboard management. The following section explains the stochastic programming models used in this paper and later gives the models for the extraboard problem. Next, numerical examples using the proposed models are presented. Then the results of these various scenarios are discussed. The paper concludes with a summary of the findings and the direction for future research.

\section{LITERATURE REVIEW}

The importance of transit operations during emergency evacuations is well established by several studies conducted after recent catastrophic events that required mass evacuations. However, development of an operational extraboard management model has not received the same level of attention as optimal routing of transit vehicles to maximize the number of people evacuated while minimizing evacuation times.

Extraboard management is studied only in the context of daily transit operations, and there is no specific study on this important problem for emergency evacuations. Although the number of studies about optimal extraboard sizing is also limited for regular operations, there is an agreement on two factors affecting the extraboard size, namely, labor contracts and the size of the fleet (1). However these constraints can be relaxed to some extent for an emergency situation because many of the state plans described in the TRB report on transit-based evacuation suggest the usage of extra resources such as school buses and their drivers as the additional capacity (3).

Earlier studies defining the extraboard management problem stated that for regular operations, the major cause of extraboard staff need is "open work," which is a term used for temporarily uncovered work assignments. Open work can be a result of unassigned service, nonoperating assignments, or operator absence ( 8 ). Open work caused by absenteeism is a major issue during an evacuation operation because the risk of losing drivers might be higher, depending on the severity of the situation. This situation was underlined in the evaluation report prepared in the aftermath of Hurricanes Katrina and Rita (4).

One of the earlier and most significant studies focusing on extraboard management for regular scheduling of transit systems was conducted by Koutsopoulos. This paper proposed models for determining the optimum number of extra operators for regular daily operations of transit systems by defining the problem at three levels: strategic, tactical, and operational. At the tactical level, determination of the required daily extraboard assignments by using the available resources was the main objective. The model attempted to minimize the expected daily difference between the available extraboard operators and the current ones who have days off. The model constraints ensured that all operators were using 2 days off per week. The author noted that the model assumes a requirement of $100 \%$ reliability. The Frank-Wolfe algorithm was used as the solution method for the continuous version of the problem. An application to a real-world example resulted in a $24 \%$ decrease per week in the expected overtime (9).

A comprehensive discussion about the reliability and absenteeism relationship, with its role in determining optimal extraboard size, was given by Shiftan and Wilson in 1994. They started their analysis by developing a disaggregate model to understand the relationship between absenteeism and overtime (i.e., trips for which extraboard drivers are needed) and estimated the model using panel data from the Massachusetts Bay Transportation Authority. They found that absenteeism is a habit that cannot be handled by reducing overtime. In other words, even if extra effort is made to cover most of the trips with regular drivers, absenteeism will not be reduced significantly, and the only solution may be enforcements through strict monitoring. The authors did not recommend generalization of their finding because it might have been data specific. They then studied the relationship between reliability and overtime using aggregate data from the Massachusetts Bay Transportation Authority. Similar to the previous research by Koutsopoulos, they measured the reliability as the expected number of missed trips and found a strong relationship between the two parameters. They concluded that it is important to take reliability into account in strategic extraboard management models (10).

Another related study by Shiftan and Wilson proposed a model to determine the optimal staff size for minimizing the total operating cost, considering a minimum desired service reliability constraint. The authors considered a global model with two stages. The first stage estimated the optimal total staff size (i.e., including extraboard as a function of the reliability constraint) for a given time (e.g., a month), and the second stage aimed to determine the annual hiring program and vacation day allocations. The authors calculated the number of extraboard personnel as the difference between required work and available manpower (11).

Different aspects of transit-based evacuation modeling are also reviewed. A number of studies on modeling routing of transit vehicles for evacuation are identified. However, none of the reviewed studies incorporates constraints related to staffing in the models. A heuristic algorithm based on the vehicle routing problem was developed by Bish to model the bus-based evacuation for a threat with advance notice (12). Transit-dependent evacuation for a no-notice disaster was also studied by Sayyady and Eksioglu. The developed model aimed to maximize the number of evacuees served during the evacuation operation (13).

The literature search reveals that no specific model has been developed to determine the optimal extraboard sizing for transitbased evacuation planning. Therefore, the contribution of this paper is twofold. First, it defines a general extraboard management model for evacuation operations with stochastic programming methods, and second, it provides techniques capable of handling the riskaverse behavior of the decision makers as well as the system service quality. One of the key points of the modeling and solution approaches is the flexibility of the models in the specific purpose they will be used for. As a direct result of this flexibility, the proposed models can be applicable to different events and multiple regions in an evacuation area.

\section{RESEARCH METHODOLOGY}

Extraboard management is a complex problem because of the uncertainty of open work. The probability of a driver to show up during regular operations can be estimated by employing the historical 
data of absenteeism resulting from certain factors such as illness or vacation. However, this process is not straightforward because of the lack of reliable recording of precise open work data. The problem gets even more complex for emergency conditions because it is difficult to predict the behavior of driver crews struggling with their own evacuation problems. External factors such as the availability of roads for access to the main hubs also affect the probability of reporting to duty. Therefore, the problem of predicting the available number of drivers under emergency conditions is highly stochastic.

If the agency can make an adequate estimation of the probability distribution of driver availability, the extraboard management problem can be formulized as a stochastic problem for different quality of service levels. The term quality of service is used for the reliability measure of the service, which also offers flexibility for the agency or decision makers to take into account various probabilities of outcomes. For example, an agency may decide to have a higher quality of service in the shore regions during a hurricane than in inland regions to avoid extra costs. This factor also brings the concept of risk into the problem because agencies' risk-taking behavior may also be an important factor in extraboard management strategy. Therefore, in this paper, the authors present two approaches to model the risk-taking behavior of decision makers.

The models in this paper are developed for an evacuation area that can consist of several regions. The idea of dividing the evacuation area into regions ensures that every region has independent needs and the capability to hire extra staff. This assumption is made because in an emergency, connections between regions can be disturbed and staff transfer between regions may not be possible. It is also considered that the driver costs can be varied depending on the region, which can get higher as the vulnerability risk increases.

Demand for drivers is assumed to be directly related to transitdependent demand by the people affected by the specific disaster. Transit-dependent demand for evacuation may vary substantially during emergencies, but considering both demand and supply as random variables may bring additional computational difficulties. Car ownership and other socioeconomic data from census reports can be useful for deterministic demand estimation that can be used by the models presented here.

Parameters that are common to both models follow:

$$
\begin{aligned}
N= & \text { number of regions; } \\
M_{i}= & \text { number of realizations of available regular drivers at region } \\
& i \in\{1, \ldots, N\} ; \\
R_{i}= & \text { random variable representing the number of available regular } \\
& \text { drivers at region } i \in\{1, \ldots, N\} \text { [its distribution is } P\left(R_{i}=\right. \\
& \left.R_{i j}=p_{i j}, j \in\left\{1, \ldots, M_{i}\right\}\right] ; \\
D_{i}= & \text { demand for drivers at region } i \in\{1, \ldots, N\} ; \\
c= & \text { cost per unit of unsatisfied demand }(\$) ; \text { and } \\
c_{i}^{x}= & \text { cost for extraboard drivers }(\$) .
\end{aligned}
$$

The decision variable (integer) used in the models is $x_{i}=$ number of extraboard drivers at region $i \in\{1, \ldots, N\}$.

\section{Model 1}

Model 1 aims to determine the optimal number of drivers for each region depending on the probability distributions for driver availabilities. Risk-averse behavior is involved in the model only in terms of a systemwide quality-of-service parameter. Thus, individual risk-taking preferences of decision makers are not captured in this model.

$\operatorname{minimize} c \sum_{i=1}^{N} \sum_{j=1}^{M_{i}} z_{i j} p_{i j}+\sum_{i=1}^{N} c_{i}^{X} x_{i}$

subject to

$P(D-x \leq R) \geq q_{\text {service }}$

$z_{i j} \geq D_{i}-R_{i j}-x_{i} \quad i \in\{1, \ldots, N\}, j \in\left\{1, \ldots, M_{i}\right\}$

$z_{i j} \geq 0 \quad i \in\{1, \ldots, N\}, j \in\left\{1, \ldots, M_{i}\right\}$

$x_{i} \geq 0$ and integer $\quad i \in\{1, \ldots, N\}$

where

$$
\begin{aligned}
z_{i j}= & \text { unsatisfied demand when there exist } R_{i j} \text { regular drivers } \\
& \text { with probability } p_{i j} ; \\
R= & \text { vector of } R_{i}, i \in\{1, \ldots, N\} \\
D= & \text { vector of } D_{i}, i \in\{1, \ldots, N\} \\
x= & \text { vector of } x_{i}, i \in\{1, \ldots, N\} ; \text { and } \\
= & \text { systemwide quality of service determined by decision } \\
& \text { makers. }
\end{aligned}
$$

The model aims to minimize the overall costs of extraboard scheduling for an emergency evacuation operation. The objective function (Equation 1) has two terms representing costs. The first term in the objective function is the total expected cost for the unsatisfied demand and the second term is the driver costs for the hired extraboard staff. Unsatisfied demand brings an indirect cost that is difficult to quantify in terms of monetary units. The interpretation of this portion of the cost model can be made by considering the costs of a possible injury or fatality because of the failure of the evacuation operation. The second cost term in the objective function is a direct cost for the extra drivers, including salaries and other benefits. Therefore, the model tries to optimize the number of extraboard drivers by considering the cost burden for the operating agency. The term "quality of service" is included in the first constraint (Equation 2 ), which gives the flexibility to determine the optimal extraboard scheduling to the decision makers for different possible situations. Here, quality of service is defined systemwide. When its value is equal to one, the constraint (Equation 2) will be satisfied with $100 \%$ certainty. Thus, it becomes a deterministic constraint. The second and third constraints are presented in Equations 3 and 4, with the objective function force $z_{i j}$ to be equal to unsatisfied demand, which is $\max \left\{0, D_{i}-R_{i j}-x_{i}\right\}$.

Model 1 is solved with the p-level efficient point (p-lep) technique. The $\mathrm{p}$-lep algorithm for a given discrete distribution was introduced by Prekopa et al., and it is an efficient and fast way of calculating the Pareto frontiers (p-efficient points) (14). The p-lep method has been employed in several studies for modeling evacuation operations, including measuring the probabilistic effects of road capacity constraints on shelter capacities for a hurricane evacuation (15), evacuation network modeling (16) and inventory management for disasters (17). [For further discussion of the theoretical background 
of the p-lep technique, see work by Prekopa et al. (14), Prekopa (18) and Dentcheva et al. (19)].

\section{Model 2}

Solving Model 1 can be computationally difficult when the number of evacuation regions is large. In this section, the authors suggest an alternative model that is linear and handles the risk by using secondorder stochastic dominance constraints. The dominance constraints require a reference distribution for the unsatisfied demand. In Model 2, the authors are interested in finding a distribution of unsatisfied demand that is at least as good as the reference distribution.

\section{Second-Order Stochastic Dominance Constraints}

Model 2 uses second-order stochastic dominance constraints, which allow decision makers to obtain a random outcome from an optimization problem that is at least as good as another reference random outcome. In this case, it is said that the resulting random outcome stochastically dominates the previously given probabilistic reference outcome.

The stochastic dominance concept is defined for different orders. Figure 1 is a graphical depiction of the concept of stochastic dominance. If higher values are preferable, first-order stochastic dominance ensures that an alternative $Y$ dominates another alternative $X$ when the cumulative distribution function of $Y$ (denoted by $F_{Y}$ ) never lies

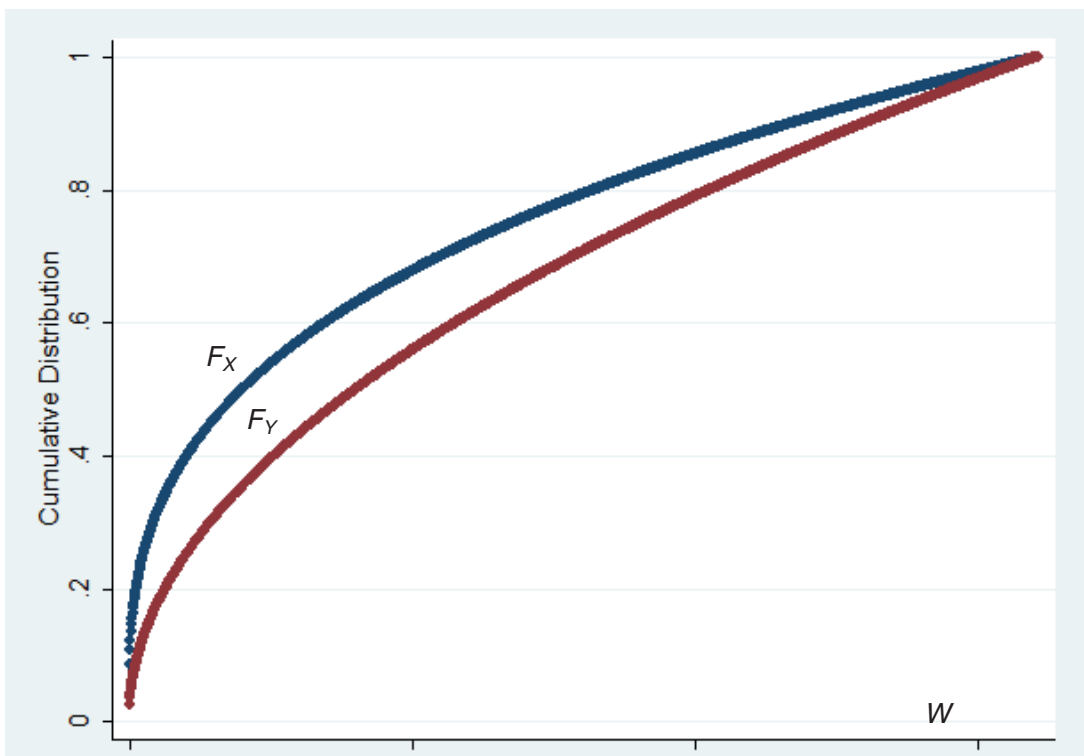

(a)

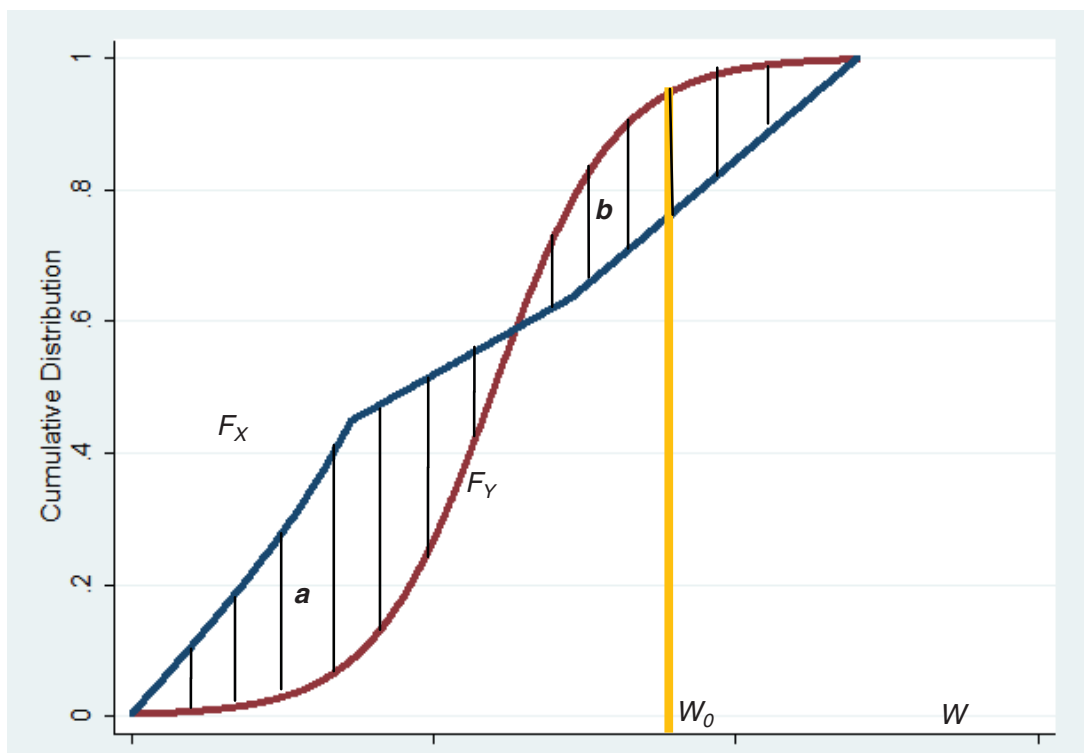

(b)

FIGURE 1 Stochastic dominance: (a) first order and $(b)$ second order. 
above the cumulative distribution of $X\left(F_{X}\right)$, where $F$ denotes the cumulative distribution function. However, first-order dominance is not always enough to explain the risk-averse behavior; therefore, higher-order stochastic dominance models are used to distinguish different risk attitudes of decision makers (20). Integrable random variables are used and risk-averse decisions are taken, depending on the areas under the curve. In Figure $1 b, Y$ dominates $X$ in the second order if the area under $F_{X}$ is not smaller than the area under $F_{Y}$ for any $W_{0}$, or in other words, $a-b \geq 0$. A comprehensive analysis of stochastic dominance relationships is given by Muller and Stoyan (21). If every risk-averse decision maker prefers an option $Y$ to $X$ (higher values are preferable for both), given that they have increasing concave utility functions, then $Y$ is said to dominate $X$ with respect to second-order stochastic dominance (SSD) and is denoted as $Y \geq_{(\mathrm{SSD})} X$. In this paper, the authors use another notation common in the literature: $Y \geq_{(2)} X$. A dual concept of second-order stochastic dominance is called increasing convex order (icx), which defines an ordering relation when lower values of $X$ and $Y$ are preferable. $Y \leq_{(\text {icx })} X$ denotes that $Y$ is less than or equal to $X$ in the sense of increasing convex order. It is known that $Y \leq_{(\text {icx) }} X$ if and only if $-Y \geq_{\text {(SSD) }}-X$ [see work by Muller and Stoyan (21) for details].

Although stochastic dominance is popular in statistics and finance areas, it remains largely unexplored in transportation research. To the knowledge of the authors, the only related study in the literature is an optimal path problem formulated by using second-order stochastic dominance constraints for analyzing risk-averse driver behavior (22).

Dentcheva and Ruszczynski introduce stochastic optimization problems with dominance constraints and study the optimality and duality conditions $(23,24)$. Model 2 , which uses second-order stochastic dominance constraints, is defined as

$\operatorname{minimize} c \sum_{i=1}^{N} \sum_{j=1}^{M_{i}} z_{i j} p_{i j}+\sum_{i=1}^{N} c_{i}^{X} x_{i}$

subject to

$$
\begin{aligned}
& -Z_{i} \geq_{(2)}-Y_{i} \quad i \in\{1, \ldots, N\} \\
& z_{i j} \geq D_{i}-R_{i j}-x_{i} \quad i \in\{1, \ldots, N\}, j \in\left\{1, \ldots, M_{i}\right\} \\
& z_{i j} \geq 0 \quad i \in\{1, \ldots, N\}, j \in\left\{1, \ldots, M_{i}\right\} \\
& x_{i} \geq 0 \text { and integer } \quad i \in\{1, \ldots, N\}
\end{aligned}
$$

where $P\left(Z_{i}=z_{i j}\right)=p_{i j}$ is demand equal to $z_{i j}$, which is not satisfied with probability $p_{i j}$, and $P\left(Y_{i}=y_{i l}\right)=f_{i l}$ is the reference distribution of unsatisfied demand at region $i$ with $l \in\left\{1, \ldots, H_{i}\right\}$.

The objective function of Model 2 is the same as that of Model 1. The first constraint (Equation 7) is introduced to find a distribution for $Z_{i}$ which is at least as good as the reference distribution. Therefore, the reference distribution should be one that is acceptable by both modelers and practitioners. Assume that the unsatisfied demand at region $i$ is distributed by $P\left(U=u_{i l}\right)=f_{i l}, i \in\{1, \ldots, N\}, l \in\left\{1, \ldots, H_{i}\right\}$ when no extraboard drivers are hired. Here $H_{i}$ is the number of realizations for the unsatisfied demand. The authors define $q_{\text {service }}^{i}$ corresponding to an improvement for the unsatisfied demand of a region $i \in\{1, \ldots, N\}$.
For the reference distribution of unsatisfied demand, the following is assumed:

$P\left(Y=y_{i l}=\left\lceil\left(1-q_{\text {service }}^{i}\right) u_{i l}\right\rceil\right)=f_{i l}$

Here $\lceil a\rceil$ denotes the smallest integer not less than $a$. Because the unsatisfied demand takes integer values, $\left(1-q_{\text {service }}^{i}\right) u_{i l}$ is rounded up to the nearest integer. A similar calculation for reference distribution can be found in work by Noyan, who used second-order stochastic dominance constraints to model the risk aversion in an emergency response facility location and allocation problem (25).

A linear formulation for the second-order stochastic dominance constrained optimization problem is introduced by Luedtke (26). Following Theorem 3.2 of Luedtke's work, the authors obtain the formulation in Equations 12 through 15 for the dominance constraint in Equation 7:

$\sum_{l=1}^{H_{i}} y_{i l} w_{i k l} \geq z_{i k} \quad i \in\{1, \ldots, N\}, k \in\left\{1, \ldots, M_{i}\right\}$

$\sum_{l=1}^{H_{i}} w_{i k l}=1 \quad i \in\{1, \ldots, N\}, k \in\left\{1, \ldots, M_{i}\right\}$

$\sum_{k=1}^{M_{i}} p_{i k} w_{i k l}=f_{i l} \quad i \in\{1, \ldots, N\}, l \in\left\{1, \ldots, H_{i}\right\}$

$w_{i k l} \geq 0 \quad i \in\{1, \ldots, N\}, k \in\left\{1, \ldots, M_{i}\right\}, l \in\left\{1, \ldots, H_{i}\right\}$

\section{Additional Constraints}

Additional constraints can be included in the models. In real-world applications, there is always a budget constraint, which can be added for driver cost as follows, where $\mathrm{UB}_{\text {budget }}$ is the upper bound for the budget:

$\sum_{i=1}^{N} c_{i}^{X} x_{i} \leq \mathrm{UB}_{\text {budget }}$

Another constraint can be used to limit the total number of extraboard drivers (where $\mathrm{UB}_{\text {total drivers }}$ is the upper bound for the total number of drivers), which is a sum of all drivers for all regions in the evacuation region. This bound may be determined from the licensed bus driver numbers in that region and can be included in the model as

$\sum_{i=1}^{N} x_{i} \leq \mathrm{UB}_{\text {total drivers }}$

The following section presents an example that illustrates the use of these models.

\section{CASE STUDY}

In this section, the authors present an example using the two models. The problem is defined for four regions with different characteristics in terms of driver demand and availability. Input parameters are 
selected to demonstrate the capabilities of the models. Driver demand is assumed to be deterministic, and the availability of drivers during an emergency condition is subject to change according to a probabilistic distribution. Assumed values are shown in Figure 2.

Regions 1 and 2 have the same number of drivers for regular conditions, but Region 1 has a larger transit-dependent population under threat. Region 2 demands the lowest number of extra drivers during evacuation, indicating neither that this region is as much under risk as other regions nor that decision makers exhibit a risk-prone behavior for this region. Region 4 has the largest number of regular drivers and the need for drivers in an emergency is also the greatest.

Probability distributions depict the certainty and uncertainty of the available number of drivers during an emergency evacuation. For example, a distribution with a sharp increase for Region 3 indicates that decision makers have a strong belief that they will have a certain number of drivers with the probability of the peak point value, whereas the probabilities of the others are considerably lower. For Region 1, there is a flat distribution, which shows a higher level of uncertainty about driver availability.

Table 1 shows the scenario definitions and model outputs. For most of the scenarios, extra driver requirements determined by Model 2 are usually greater than or equal to the numbers obtained from Model 1. This difference is the cause of higher total costs for Model 2. For the first eight scenarios in which unsatisfied demand cost is assumed to

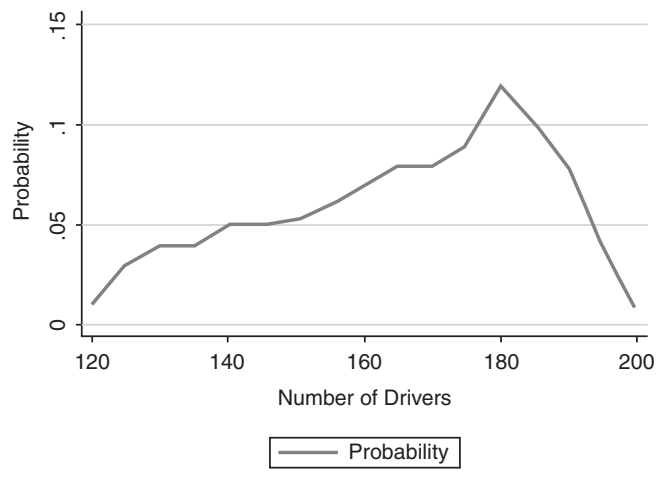

(a)

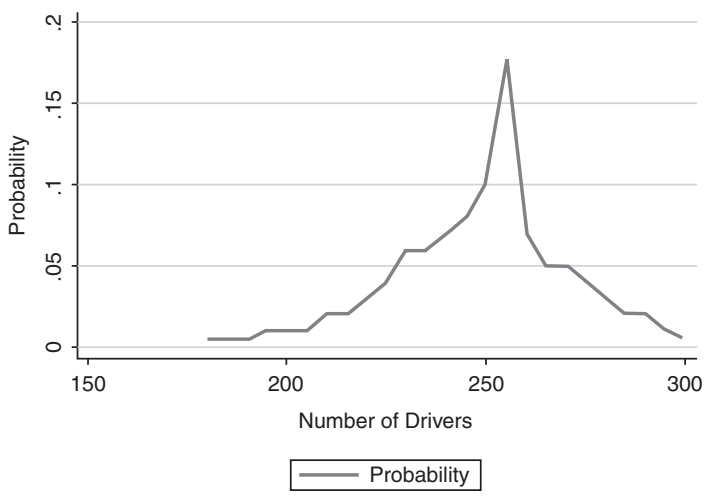

(c) be in a similar range with driver costs, Model 1 seems to be more sensitive to the marginal changes in driver costs. For Scenarios 9 through 12, for which considerably higher unsatisfied demand costs are assumed, both models try to keep the extra driver numbers as high as possible.

Both models generate reasonable results under different scenarios, and it is difficult to conclude that either model is superior to the other. In a real-world setting, decision makers can use the results obtained from both models to build a range for extra workforce requirements for an evacuation operation for a number of likely scenarios ranging from a worst case scenario to an average scenario to an optimistic scenario. Incorporating different quality-of-service values will enable a comprehensive sensitivity analysis, which will provide valuable information to reduce the risk of failure in case of transporting a transit-dependent population.

Different quality-of-service levels are also tested to observe the sensitivity of the models with respect to the quality-of-service preferences. The reason for selecting the two scenarios is that Scenario 2 assumes all the cost measures in the objective function are the same, and Scenario 1 assumes the cost for unsatisfied demand is relatively higher than the cost for drivers. Therefore, sensitivity of the models is tested for two distinctly different cost structures.

The results of the sensitivity analysis are shown in Table 2 . According to Scenario 1, the results of both models are conservative

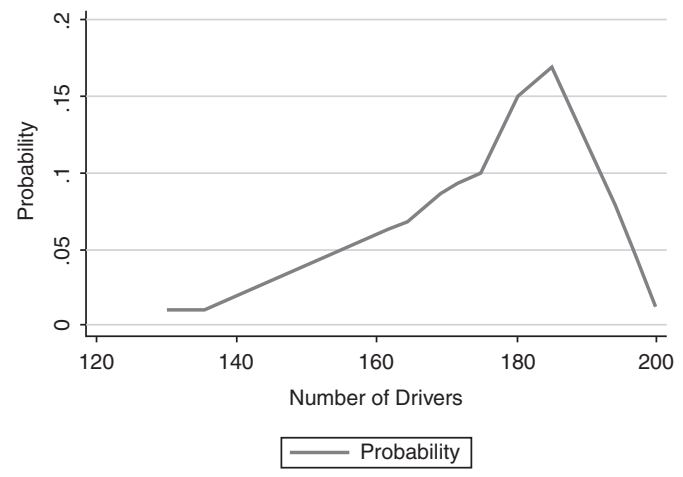

(b)

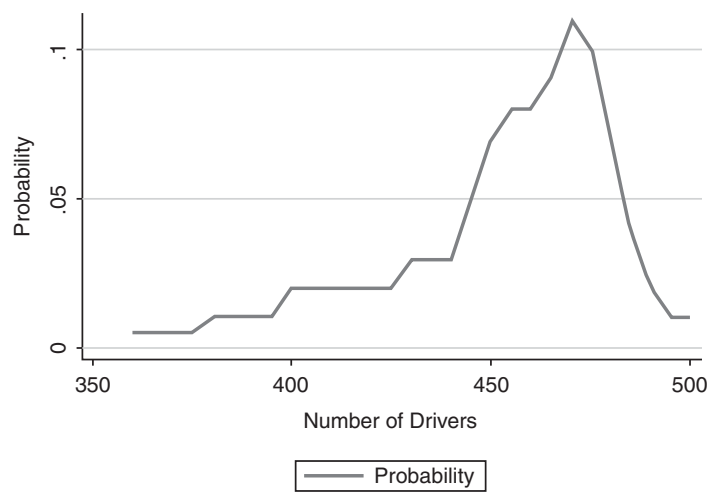

(d)

FIGURE 2 Regional characteristics and assumed hypothetical probability distributions for driver availabilities for the example problem: (a) Region 1, regular number of drivers $=200$, demand for drivers during evacuation $=250$; (b) Region 2, regular number of drivers $=200$, demand for drivers during evacuation $=240$; $(c)$ Region 3 , regular number of drivers $=300$, demand for drivers during evacuation = 350; and (d) Region 4, regular number of drivers $=500$, demand for drivers during evacuation $=570$. 
TABLE 1 Scenario Definitions and Model Results

\begin{tabular}{|c|c|c|c|c|c|c|c|c|c|c|c|c|c|c|c|}
\hline \multirow[b]{3}{*}{ Scenario } & & & & & \multirow{3}{*}{$\begin{array}{l}\text { Unsatisfied } \\
\text { Demand Cost } \\
\text { (\$) }\end{array}$} & \multicolumn{5}{|l|}{ Model 1} & \multicolumn{5}{|l|}{ Model 2} \\
\hline & \multicolumn{4}{|c|}{ 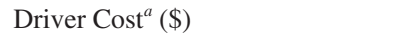 } & & \multirow{2}{*}{$\begin{array}{l}\text { Total Cost } \\
\text { (\$) }\end{array}$} & \multicolumn{4}{|c|}{ Number of Extra Drivers } & \multirow{2}{*}{$\begin{array}{l}\text { Total Cost } \\
(\$)\end{array}$} & \multicolumn{4}{|c|}{ Number of Extra Drivers } \\
\hline & $c_{1}^{x}$ & $c_{2}^{x}$ & $c_{3}^{x}$ & $c_{4}^{x}$ & & & $x_{1}$ & $x_{2}$ & $x_{3}$ & $x_{4}$ & & $x_{1}$ & $x_{2}$ & $x_{3}$ & $x_{4}$ \\
\hline 1 & 100 & 100 & 100 & 100 & 5,000 & 60,000 & 125 & 105 & 155 & 195 & 60,000 & 125 & 102 & 155 & 190 \\
\hline 2 & 100 & 100 & 100 & 100 & 100 & 55,605 & 125 & 100 & 145 & 185 & 55,916 & 117 & 99 & 153 & 189 \\
\hline 3 & 1,000 & 100 & 100 & 100 & 100 & 162,080 & 115 & 110 & 160 & 200 & 161,216 & 117 & 99 & 153 & 189 \\
\hline 4 & 100 & 1,000 & 100 & 100 & 100 & 138,100 & 130 & 90 & 155 & 195 & 145,016 & 117 & 99 & 153 & 189 \\
\hline 5 & 100 & 100 & 100 & 100 & 100 & 173,657 & 130 & 110 & 130 & 195 & 193,616 & 117 & 99 & 153 & 189 \\
\hline 6 & 100 & 100 & 1,000 & 1,000 & 100 & 201,205 & 130 & 110 & 170 & 160 & 226,016 & 117 & 99 & 153 & 189 \\
\hline 7 & 100 & 200 & 100 & 100 & 100 & 65,593 & 125 & 95 & 150 & 190 & 65,816 & 117 & 99 & 153 & 189 \\
\hline 8 & 100 & 200 & 100 & 100 & 5,000 & 70,000 & 125 & 100 & 155 & 190 & 70,000 & 125 & 99 & 155 & 190 \\
\hline 9 & 1,000 & 100 & 100 & 100 & 10,000 & 170,000 & 115 & 110 & 160 & 205 & 170,400 & 117 & 105 & 160 & 200 \\
\hline 10 & 100 & 1,000 & 100 & 100 & 10,000 & 147,500 & 130 & 90 & 160 & 200 & 151,400 & 125 & 99 & 160 & 200 \\
\hline 11 & 100 & 100 & 1,000 & 100 & 10,000 & 189,000 & 130 & 110 & 130 & 200 & 199,750 & 125 & 105 & 153 & 200 \\
\hline 12 & 100 & 100 & 100 & 1,000 & 10,000 & 221,250 & 130 & 110 & 165 & 165 & 232,550 & 125 & 105 & 160 & 189 \\
\hline
\end{tabular}

${ }^{a} c_{1}, c_{2}, c_{3}$, and $c_{4}$ are the costs for regions $1,2,3$, and 4 , respectively; $x=$ number of extraboard drivers for each region.

when the unsatisfied demand cost is assumed to be higher than the driver cost.

Results of Scenario 2 show more diverse results as the qualityof-service level changes. In this case, unsatisfied demand costs are assumed to be at the same level as driver costs. Figure 3 shows the changes in total costs: that Model 2 is more sensitive to the varying quality-of-service levels than Model 1.

Table 3 depicts the model results when additional constraints (budget and the number of drivers) are used. When the driver budget cap is decreased, both models try to rearrange the extraboard assignments and the total number of extra drivers decreases; however, total costs rise because of the increase in unsatisfied demand. Similar behavior can be seen for the constraint on the number of drivers as well. These results confirm that both models successfully reflect the possible changes in availability of physical and monetary resources for the evacuation operation.

\section{HYPOTHETICAL SCENARIO BASED ON REAL-WORLD DATA}

In this section, the developed models are tested for a hypothetical evacuation scenario in northern New Jersey. A primary reason for testing the model with data from real transit operations is to observe the interpretation of unsatisfied demand cost in the proposed models; this step can be challenging for practical applications. Therefore, in this example, the authors take the unsatisfied demand cost as unknown and try to estimate its value while taking all other parameters from real examples. New Jersey has significant transit usage, and the percentage of households that do not have access to automobiles is higher than the national average (27). This population will need to use transit in an evacuation; therefore, ensuring maintenance of adequate transit service is critical. Figure 4 shows the six New Jersey counties selected as the possible evacuation regions, evacuation

TABLE 2 Results for Different Quality-of-Service Levels

\begin{tabular}{|c|c|c|c|c|c|c|c|c|c|c|}
\hline \multirow{3}{*}{$\begin{array}{l}\text { Quality of } \\
\text { Service (\%) }\end{array}$} & \multicolumn{5}{|l|}{ Model 1} & \multicolumn{5}{|l|}{ Model 2} \\
\hline & \multirow[b]{2}{*}{ Total Cost (\$) } & \multicolumn{4}{|c|}{ Number of Extra Drivers } & \multirow[b]{2}{*}{ Total Cost (\$) } & \multicolumn{4}{|c|}{ Number of Extra Drivers } \\
\hline & & $x_{1}$ & $x_{2}$ & $x_{3}$ & $x_{4}$ & & $x_{1}$ & $x_{2}$ & $x_{3}$ & $x_{4}$ \\
\hline \multicolumn{11}{|l|}{ Scenario 1} \\
\hline 0.95 & 60,000 & 125 & 105 & 155 & 195 & 60,275 & 125 & 105 & 161 & 199 \\
\hline 0.9 & 60,000 & 125 & 105 & 155 & 195 & 60,000 & 125 & 102 & 155 & 190 \\
\hline 0.85 & 60,000 & 125 & 105 & 155 & 195 & 60,000 & 125 & 100 & 155 & 190 \\
\hline 0.8 & 60,000 & 125 & 105 & 155 & 195 & 60,000 & 125 & 100 & 155 & 190 \\
\hline \multicolumn{11}{|l|}{ Scenario 2} \\
\hline 0.95 & 58,040 & 125 & 105 & 155 & 195 & 58,735 & 123 & 104 & 161 & 199 \\
\hline 0.9 & 55,605 & 125 & 100 & 145 & 185 & 55,916 & 117 & 99 & 153 & 189 \\
\hline 0.85 & 53,692 & 120 & 105 & 140 & 175 & 52,793 & 110 & 93 & 144 & 178 \\
\hline 0.8 & 52,275 & 120 & 95 & 135 & 170 & 50,148 & 104 & 88 & 136 & 168 \\
\hline
\end{tabular}




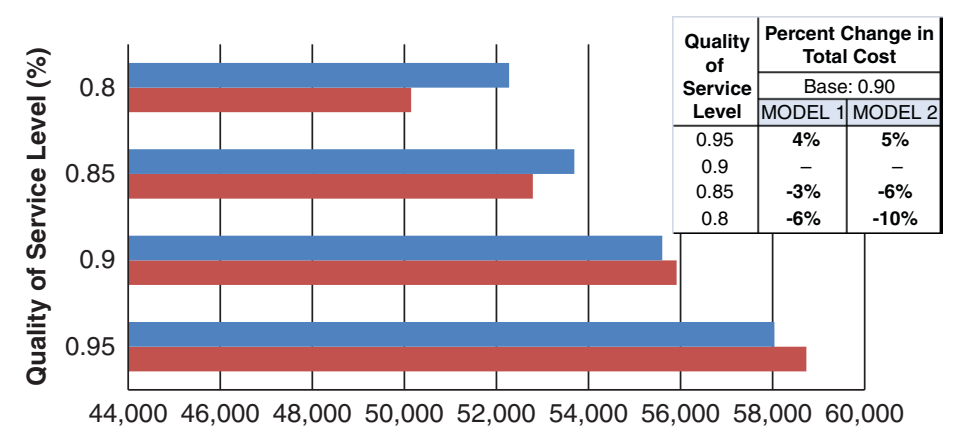

\begin{tabular}{|l|c|c|c|c|}
\cline { 2 - 5 } \multicolumn{1}{c|}{} & 0.95 & 0.9 & 0.85 & 0.8 \\
\hline MODEL 1 & 58,040 & 55,605 & 53,692 & 52,275 \\
\hline MODEL 2 & 58,735 & 55,916 & 52,793 & 50,148 \\
\hline \multicolumn{4}{c}{ Total Cost }
\end{tabular}

FIGURE 3 Change in total cost by quality-of-service level.

demand, and the number of bus drivers for regular operations and evacuation operations. Evacuation demand is determined from telephone surveys that were conducted from random samples from New Jersey. Survey results enable decision makers to examine the evacuation decision changes, possible destinations, and mode choice for different threat types. More details about this survey can be found in work by Ozbay et al. (28) and Carnegie and Deka (29). The number of drivers required under nonemergency conditions is from the North Jersey Regional Transportation Model-Enhanced, a calibrated travel demand model developed by the North Jersey Transportation Planning Authority (30).

Realistic probability distribution for driver availability, which is given in Figure 4, is obtained from Metropolitan Transportation Authority bus employee lost time data, which are publicly available

TABLE 3 Results for Additional Constraints

\begin{tabular}{|c|c|c|c|c|c|c|c|c|c|c|}
\hline \multirow[b]{3}{*}{ Value } & \multicolumn{5}{|l|}{ Model 1} & \multicolumn{5}{|l|}{ Model 2} \\
\hline & \multirow{2}{*}{$\begin{array}{l}\text { Total } \\
\text { Cost }(\$)\end{array}$} & \multicolumn{4}{|c|}{ Number of Extra Drivers } & \multirow{2}{*}{$\begin{array}{l}\text { Total } \\
\text { Cost }(\$)\end{array}$} & \multicolumn{4}{|c|}{ Number of Extra Drivers } \\
\hline & & $x_{1}$ & $x_{2}$ & $x_{3}$ & $x_{4}$ & & $x_{1}$ & $x_{2}$ & $x_{3}$ & $x_{4}$ \\
\hline \multicolumn{11}{|c|}{ Cap on Driver Budgets } \\
\hline No cap & 61,500 & 125 & 110 & 160 & 205 & 61,500 & 125 & 105 & 160 & 200 \\
\hline$\$ 60,000$ & 61,500 & 125 & 110 & 160 & 205 & 61,500 & 125 & 105 & 160 & 200 \\
\hline$\$ 59,000$ & 61,500 & 125 & 110 & 160 & 205 & 61,500 & 125 & 105 & 160 & 200 \\
\hline$\$ 58,000$ & 62,000 & 125 & 105 & 155 & 195 & 62,000 & 125 & 105 & 155 & 195 \\
\hline$\$ 57,000$ & 63,000 & 125 & 100 & 155 & 190 & 63,000 & 125 & 100 & 155 & 190 \\
\hline$\$ 56,000$ & 64,750 & 125 & 100 & 150 & 185 & 66,000 & 119 & 99 & 153 & 189 \\
\hline$\$ 55,000$ & na & - & - & - & - & na & - & - & - & - \\
\hline \multicolumn{11}{|c|}{ Cap on Number of Drivers } \\
\hline No cap & 61,500 & 125 & 110 & 160 & 205 & 61,500 & 125 & 105 & 160 & 200 \\
\hline 595 & 61,500 & 125 & 105 & 160 & 205 & 61,500 & 125 & 105 & 160 & 200 \\
\hline 590 & 61,500 & 125 & 105 & 160 & 200 & 61,500 & 125 & 105 & 160 & 200 \\
\hline 585 & 61,750 & 125 & 105 & 155 & 200 & 61,750 & 125 & 105 & 155 & 200 \\
\hline 580 & 62,000 & 125 & 105 & 155 & 195 & 62,000 & 125 & 105 & 155 & 195 \\
\hline 575 & 62,500 & 125 & 100 & 155 & 195 & 62,500 & 125 & 100 & 155 & 195 \\
\hline 570 & 63,000 & 125 & 100 & 155 & 190 & 63,000 & 125 & 100 & 155 & 190 \\
\hline 565 & 63,750 & 125 & 100 & 150 & 190 & 64,100 & 124 & 99 & 153 & 189 \\
\hline 560 & 64,750 & 125 & 100 & 150 & 185 & 66,000 & 119 & 99 & 153 & 189 \\
\hline 558 & 65,250 & 125 & 100 & 148 & 185 & 67,400 & 117 & 99 & 153 & 189 \\
\hline 555 & 66,000 & 125 & 100 & 145 & 185 & na & - & - & - & - \\
\hline 550 & na & - & - & - & - & na & - & - & - & - \\
\hline
\end{tabular}

NOTE: na $=$ not applicable; $-=$ infeasible. 
Evacuation Region

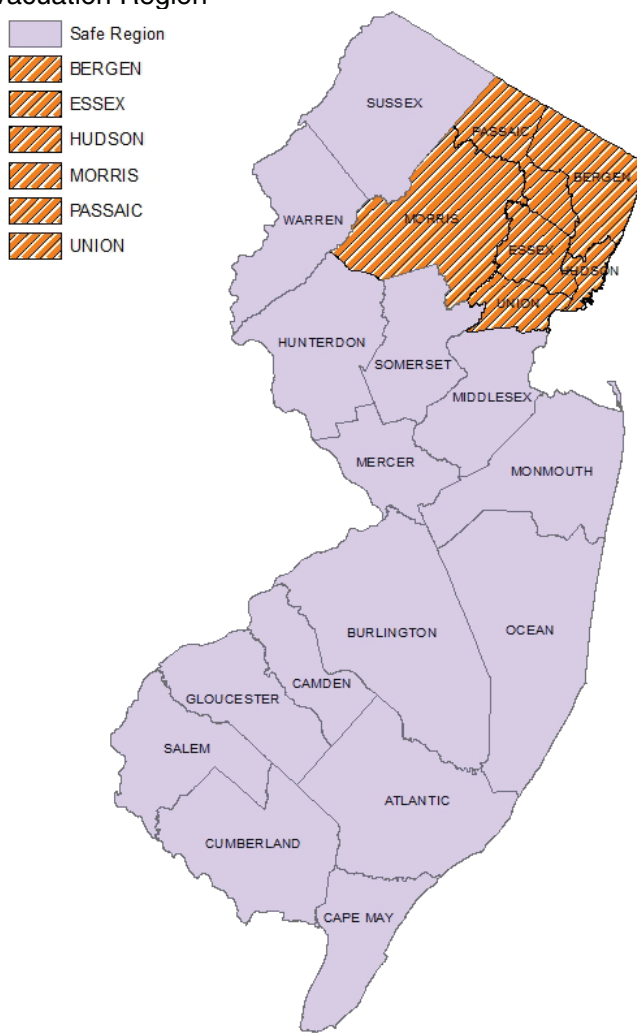

1. NJRTM-E Travel Demand Model

2. Estimations Based on Telephone Survey

\begin{tabular}{|l|r|r|r|r|r|}
\hline \multicolumn{1}{|c|}{ County } & $\begin{array}{c}\text { Total } \\
\text { Population }\end{array}$ & $\begin{array}{c}\text { Affected } \\
\text { Population }\end{array}$ & $\begin{array}{c}\text { Evacuating } \\
\text { Population }\end{array}$ & \multicolumn{1}{c|}{ Rate } & $\begin{array}{c}\text { Estimated } \\
\text { Demand }\end{array}$ \\
\hline Bergen & 884,118 & 368,701 & 690,900 & $1.8 \%$ & 12,121 \\
\hline Essex & 793,633 & 683,583 & 579,836 & $2.4 \%$ & 13,719 \\
\hline Hudson & 608,975 & 608,975 & 132,563 & $8.6 \%$ & 11,439 \\
\hline Morris & 470,212 & 0 & 395,136 & $0.7 \%$ & 1,950 \\
\hline Passaic & 489,049 & 135,045 & 381,697 & $0.5 \%$ & 5,764 \\
\hline Union & 522,541 & 248,803 & 378,155 & $1.5 \%$ & 3,915 \\
\hline Region Total & $\mathbf{3 , 7 6 8 , 5 2 8}$ & $\mathbf{2 , 0 4 5 , 1 0 7}$ & $\mathbf{2 , 5 5 8 , 2 8 7}$ & & $\mathbf{4 8 , 9 0 7}$ \\
\hline
\end{tabular}

\begin{tabular}{|c|c|c|}
\cline { 2 - 3 } \multicolumn{1}{c|}{} & $\begin{array}{c}\text { Regular } \\
\text { Case } \\
\text { Number } \\
\text { of } \\
\text { Drivers }\end{array}$ & $\begin{array}{c}\text { Est. of Buses } \\
\text { Needed }^{\mathbf{1}}\end{array}$ \\
\hline Bergen & 268 & 303 \\
\hline Essex & 302 & 343 \\
\hline Hudson & 255 & 286 \\
\hline Morris & 18 & 49 \\
\hline Passaic & 107 & 144 \\
\hline Union & 75 & 98 \\
\hline TOTAL & $\mathbf{1 , 0 2 5}$ & $\mathbf{1 , 2 2 3}$ \\
\hline
\end{tabular}
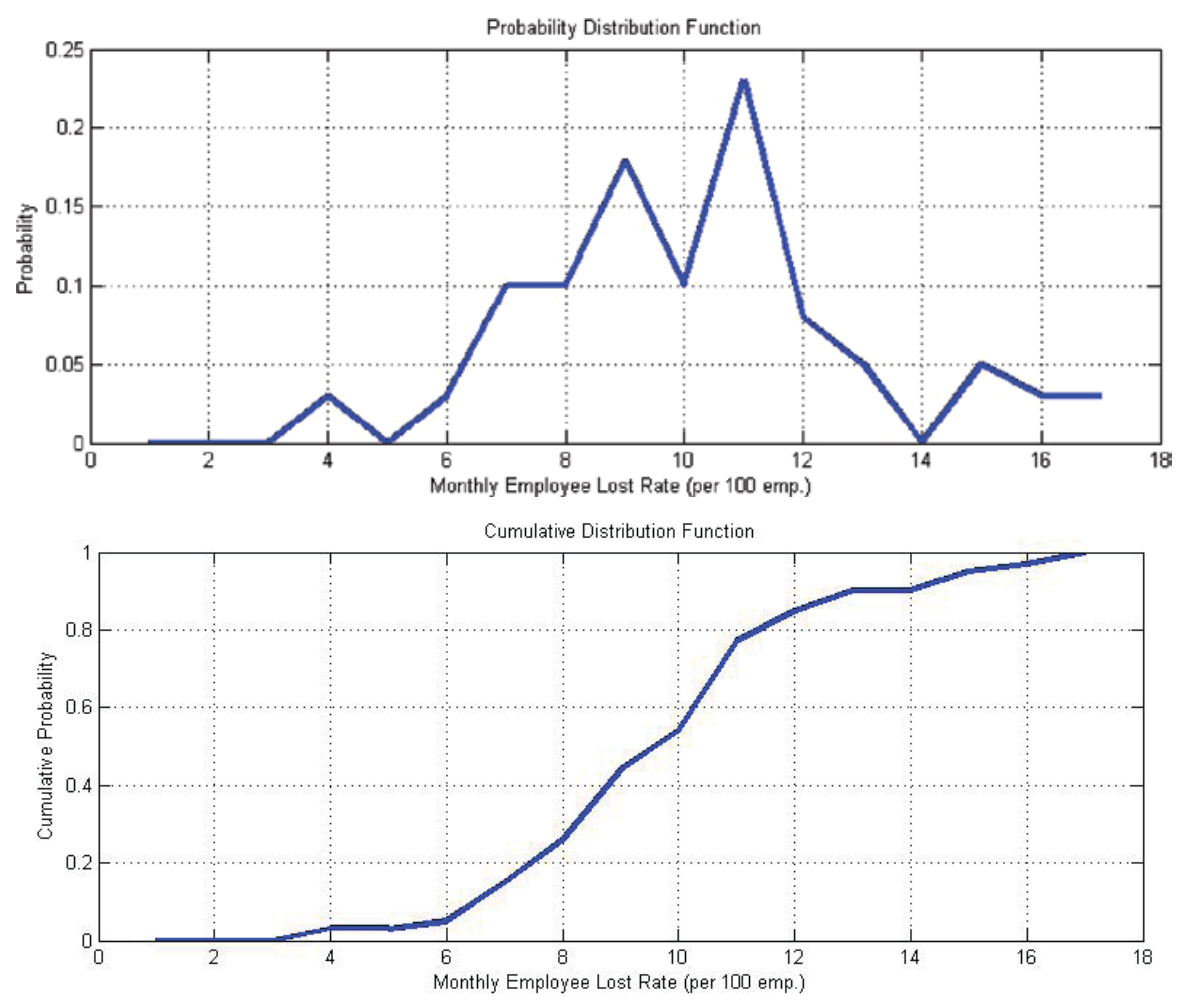

FIGURE 4 Hypothetical evacuation scenario based on real-world data (29-31) (est. = estimation; NJRTM-E = North Jersey Regional Transportation Model-Enhanced; emp. = employees]. 
monthly data (http://www.mta.info/developers/) that show the number of workers who did not show up for the shift they were assigned because of illness, injury, and other reasons. The data cover 4 years (2008 to 2012) and the probability distributions are estimated for the number of unavailable drivers per 100 employees (31). Metropolitan Transportation Authority buses operate in New York City, which is assumed to have similar characteristics to the study region in New Jersey.

For real-world applications, quantification of unsatisfied demand costs is not straightforward and various risk measures should be taken into account. Previous literature focuses on the value of life for economic analysis (32-35), but no cost estimation study was found for the case of an emergency evacuation. A meta-analysis by Mrozek and Taylor reveals that the value-of-life estimations vary between $\$ 20,000$ and $\$ 30.7$ million per fatality (33). Assuming a higher value of life for a mass evacuation could cause an overestimation of the social costs. Therefore, for the selected case study, estimation for the unsatisfied demand cost is performed by using the estimated budget cap. The North Jersey Transportation Planning Authority annual budget was reported as $\$ 2$ billion for 2011 (36). A rough estimation by Litman for the cost of total evacuation transportation for the transitbased population is given to be $20 \%$ of the annual budget of the transportation agency which equals to $\$ 400,000$ for the study region (4). This amount is assumed to be the budget cap for the operations. Clearly, cost resulting from loss of life is an extreme situation used to test an upper bound. In real life, delay in transit service is expected to have less severe impacts, such as minor inconveniences or nonfatal injuries. Two different cases are considered. First, the high estimate assumes that the agency spends its entire available budget for transit operations. Second, the low estimate assumes that the agency spends half of its available budget for evacuation operations.

Model results are shown in Table 4. Driver costs are assumed to be $\$ 100, \$ 250$, and $\$ 500$ per one bus run. For the high estimate, unsatisfied demand costs are found to range from $\$ 1.14$ million to $\$ 710,000$ and for the low estimate they range from $\$ 518,000$ to $\$ 82,000$ for the given models. These examples show that the unsatisfied demand cost case is consistent with the existing value-of-life literature reported in the meta-analysis (33). The cost associated with the loss of productivity and cost of injury can also be incorporated in the same cost. Therefore, further analysis can be conducted to better explain the unsatisfied demand cost. However, value-of-life analyses in the literature also consider most of these social costs, which are difficult to monetize in a generalized way. Therefore, the findings in this paper can also be used to verify the validity of the extraboard management models.

\section{CONCLUSION}

In this study, strategic extraboard planning and management for transit-based emergency evacuations is modeled with two stochastic optimization models developed to determine the optimum number of extra drivers. Transit evacuation models in the literature generally focus on the optimization of routing, and to the best knowledge of the research team, there are no published studies analytically combining extraboard management and evacuation modeling.

The modeling methodology used in this work tries to approach this problem from a stochastic point of view because a number of uncertainties exist on the supply side. Two different stochastic programming models for the risk-taking behavior of decision makers are suggested.

The proposed models are tested with a numerical example for different cost scenarios. Model results for the case study are found to be promising for real-life applications because they allow an agency to make a reliable prediction of the need for extra drivers for evacuation planning under various stochastic constraints. Moreover, the models allow the use of a desired quality-of-service level that can be agency and event related. This kind of information allows for the better development of customized policies for each region. Finally, an interpretation of the unsatisfied demand cost is given, with a hypothetical evacuation scenario with real-world data. Estimations are found to be consistent with the existing value of life studies. The two components of the cost function (i.e., driver costs and unsatisfied demand costs) are useful in deciding the effect of a certain policy on the out-of-pocket agency costs as well as external costs to society as a result of possible injuries, loss of life, or both.

TABLE 4 Scenario Results

\begin{tabular}{|c|c|c|c|c|c|c|c|c|}
\hline \multirow{2}{*}{$\begin{array}{l}\text { Driver } \\
\text { Cost }(\$)\end{array}$} & \multirow{2}{*}{$\begin{array}{l}\text { Unsatisfied } \\
\text { Demand } \\
\text { Cost (\$) }\end{array}$} & \multirow[b]{2}{*}{ Total Cost $(\$)$} & \multicolumn{6}{|c|}{ Number of Extra Drivers } \\
\hline & & & $x_{1}$ & $x_{2}$ & $x_{3}$ & $x_{4}$ & $x_{5}$ & $x_{6}$ \\
\hline \multicolumn{9}{|c|}{ High Estimate Results ( $\$ 400,000$ budget) } \\
\hline \multicolumn{9}{|l|}{ Model 1} \\
\hline 100 & $1,140,000$ & 397,904 & 73 & 83 & 69 & 33 & 54 & 35 \\
\hline 250 & 980,000 & 398,978 & 73 & 83 & 69 & 33 & 54 & 35 \\
\hline 500 & 710,000 & 399,706 & 73 & 83 & 69 & 33 & 54 & 35 \\
\hline \multicolumn{9}{|l|}{ Model 2} \\
\hline 100 & $1,140,000$ & 363,704 & 74 & 86 & 69 & 33 & 52 & 33 \\
\hline 250 & 980,000 & 369,578 & 74 & 86 & 69 & 33 & 52 & 33 \\
\hline 500 & 710,000 & 378,406 & 74 & 86 & 69 & 33 & 52 & 33 \\
\hline \multicolumn{9}{|c|}{ Low Estimate Results ( $\$ 200,000$ budget) } \\
\hline \multicolumn{9}{|l|}{ Model 1} \\
\hline 100 & 518,000 & 199,734 & 73 & 83 & 69 & 33 & 54 & 35 \\
\hline 250 & 355,000 & 199,853 & 73 & 83 & 69 & 33 & 54 & 35 \\
\hline 500 & 82,000 & 199,625 & 73 & 83 & 69 & 33 & 54 & 35 \\
\hline \multicolumn{9}{|l|}{ Model 2} \\
\hline 100 & 518,000 & 184,194 & 74 & 86 & 69 & 33 & 52 & 33 \\
\hline 250 & 355,000 & 189,203 & 74 & 86 & 69 & 33 & 52 & 33 \\
\hline 500 & 82,000 & 197,165 & 74 & 86 & 69 & 33 & 52 & 33 \\
\hline
\end{tabular}


There are currently no models and tools for decision makers to use to make informed decisions to determine the number of extraboard drivers they need to guarantee a certain level of service under emergency conditions. The models proposed in this paper are an attempt to address this issue and provide decision makers with a set of new reliable models. Because of the high level of uncertainty during evacuation events, stochastic models that can take into account the probabilities of a set of outcomes are developed. Proposed stochastic models can clearly help emergency planning by estimating the minimum number of drivers for different levels of quality of service under different demand, supply, and budget constraints. The immediate next step is a functionality that will allow the use of historical data for the estimation of different probability distributions required by both models. The research team also plans to implement these models in a user-friendly tool that enables users to easily create various if-then scenarios and get comparative results for quick decision making. Transportation planners can use a computer application developed with the provided models and reliability preferences developed from their own historical data for several different events where extraboard management is important.

\section{REFERENCES}

1. DeAnnuntis, C. P., and W. P. Morris. Transit Extraboard Management Optimum Sizing and Strategies. In Transportation Research Record: Journal of the Transportation Research Board, No. 2072, Transportation Research Board of the National Academies, Washington, D.C., 2008, pp. 110-124.

2. National Center for Transit Research, Center for Urban Transportation Research, University of South Florida. Transit Extraboard Management: Optimum Sizing and Strategies. Final report. Florida Department of Transportation, Tallahassee, 2007.

3. Special Report 294: The Role of Transit in Emergency Evacuation. Transportation Research Board of the National Academies, Washington, D.C., 2008.

4. Litman, T. Lessons from Katrina and Rita: What Major Disasters Can Teach Transportation Planners. Journal of Transportation Engineering, Vol. 132, No. 1, 2006, pp. 11-18.

5. Jenkins, B. M., and F. Edwards-Winslow. Saving City Lifelines: Lessons Learned in the 9-11 Terrorist Attacks. MTI Report 02-06. Mineta Transportation Institute, San Jose State University, Calif., 2003. http:// transweb.sjsu.edu/mtiportal/research/publications/documents/Sept11. book.htm. Accessed Feb. 28, 2012.

6. Naghawi, H., and B. Wolshon. Transit-Based Emergency Evacuation Simulation Modeling. Journal of Transportation Safety and Security, Vol. 2, 2010, pp. 184-201.

7. Managing Pedestrians During Evacuation of Metropolitan Areas. Publication FHWA-HOP-07-066. FHWA, U.S. Department of Transportation, 2007.

8. MacDorman, L. C. NCTRP Synthesis of Transit Practice 5: Extraboard Management: Procedure and Tools. TRB, National Research Council, Washington, D.C., 1985.

9. Koutsopoulos, H. N. Scheduling of Extraboard Operators in Transit Systems. Transportation Science, Vol. 24, No. 2, 1990, pp. 87-104.

10. Shiftan, Y., and N. H. M. Wilson. Absence, Overtime, and Reliability Relationships in Transit Workforce Planning. Transportation Research Part A: Policy and Practice, Vol. 28, No. 3, 1994, pp. 245-258.

11. Shiftan, Y., and N. H. M. Wilson. Public Transport Workforce Sizing Recognizing the Service Reliability Objective. In Computer-Aided Scheduling of Public Transport, Springer-Verlag, Berlin, 1995, pp. 248-266.

12. Bish, D. Planning for a Bus-Based Evacuation. OR Spectrum, Vol. 33, No. 3, 2011, pp. 629-654.

13. Sayyady, F., and S. D. Eksioglu. Optimizing the Use of Public Transit System During No-Notice Evacuation of Urban Areas. Computers and Industrial Engineering, Vol. 59, No. 4, 2010, pp. 488-495.

14. Prekopa, A., B. Vizvari, and T. Badics. Programming Under Probabilistic Constraint with Discrete Random Variables. In New Trends in Mathematical Programming (F. Giannessi and T. Rapcsak, eds.), Kluwer Academic Publishers, Dordrecht, Netherlands, 1998, pp. 235-257.
15. Yazici, M. A., and K. Ozbay. Impact on Probabilistic Road Capacity Constraints on the Spatial Distribution of Hurricane Evacuation Shelter Capacities. In Transportation Research Record: Journal of the Transportation Research Board, No. 2022, Transportation Research Board of the National Academies, Washington, D.C., 2007, pp. 55-62.

16. Yazici, A., and K. Ozbay. Evacuation Network Modeling via Dynamic Traffic Assignment with Probabilistic Demand and Capacity Constraints. In Transportation Research Record: Journal of the Transportation Research Board, No. 2196, Transportation Research Board of the National Academies, Washington, D.C., 2010, pp. 11-20.

17. Ozguven, E. E., and K. Ozbay. A Secure and Efficient Inventory Management System for Disasters. Transportation Research Part C: Emerging Technologies, Vol. 29, April 2013, pp. 171-196.

18. Prekopa, A. Dual Method for a One-Stage Stochastic Programming Problem with Random RHS Obeying a Discrete Probability Distribution. Mathematical Methods of Operations Research, Vol. 34, No. 6, 1990, pp. $441-461$.

19. Dentcheva, D., P. Prekopa, and A. Ruszczynski. Concavity and Efficient Points of Discrete Distributions in Probabilistic Programming. Mathematical Programming, Vol. 89, No. 1, 2000, pp. 55-77.

20. Hun Seog, S. The Economics of Risk and Insurance. John Wiley and Sons, New York, 2010.

21. Muller, A., and D. Stoyan. Comparison Methods for Stochastic Models and Risks. Wiley Series in Probability and Statistics. John Wiley and Sons, New York, 2002.

22. Nie, Y., X. Wu, and T. Homen-de-Mello. Optimal Path Problems with Second-Order Stochastic Dominance Constraints. Networks and Spatial Economics, No. 12, 2012, pp. 561-587.

23. Dentcheva, D., and A. Ruszczynski. Optimization with Stochastic Dominance Constraints. SIAM Journal on Optimization, Vol. 14, No. 2, 2003, pp. 548-566.

24. Dentcheva, D., and A. Ruszczynski. Optimality and Duality Theory for Stochastic Optimization Problems with Nonlinear Dominance Constraints. Mathematical Programming, Vol. 99, 2004, pp. 329-350.

25. Noyan, N. Alternate Risk Measures for Emergency Medical Service System Design. Annals of Operations Research, Vol. 181, No. 1, 2010, pp. 559-589.

26. Luedtke, J. New Formulations for Optimization under Stochastic Dominance Constraints. SIAM Journal on Optimization, Vol. 19, No. 3, 2008 , pp. 1433-1450.

27. Bureau of Transportation Statistics, U.S. Department of Transportation. National Household Survey. http://www.bts.gov/programs/national household_travel_survey/. Accessed June 28, 2012.

28. Ozbay, K., M. A. Yazici, S. Iyer, J. Li, E. E. Ozguven, and J. A. Carnegie. Use of Regional Transportation Planning Tool for Modeling Emergency Evacuation: Case Study of Northern New Jersey. In Transportation Research Record: Journal of the Transportation Research Board, No. 2312, Transportation Research Board of the National Academies, Washington, D.C., 2012, pp. 89-97.

29. Carnegie, J., and D. Deka. Using Hypothetical Disaster Scenarios to Predict Evacuation Behavioral Response. Presented at 89th Annual Meeting of the Transportation Research Board, Washington, D.C., 2010

30. North Jersey Transportation Planning Authority. North Jersey Regional Transportation Model-Enhanced (NJRTM-E). 2012. http://www.njtpa. org/DataMap/Perf/Model/default.aspx. Accessed Nov. 15, 2012.

31. Metropolitan Transportation Authority, New York. Bus Employee Lost Time Data, 2012. http://www.mta.info/developers/. Accessed Jan. 8, 2012.

32. Viscusi, W. The Value of Life: Estimates with Risks by Occupation and Industry. Discussion Paper 422. Harvard Law School, Cambridge, Mass., 2003. http://www.law.harvard.edu/programs/olin_center/.Accessed Nov. 13, 2012.

33. Mrozek, J. R., and L. Taylor. What Determines the Value of Life? A Meta Analysis. Journal of Policy Analysis and Management, Vol. 21, No. 2, 2002, pp. 253-270.

34. Blomquist, G. Value of Life Saving: Implications of Consumption Activity. Journal of Political Economy, Vol. 87, No. 31, 1979, pp. 540-558.

35. Blaeij, A., R. Florax, P. Rietveld, and E. Verhoef. The Value of Statistical Life in Road Safety, A Meta-Analysis. Accident Analysis and Prevention, Vol. 35, 2003, pp. 973-986.

36. Unified Planning Work Program: Budget Book Year 2 Update. North Jersey Transportation Planning Authority, Newark, 2011. http://www. njtpa.org/About/Business/documents/FY2012_UPWP_Budget_000.pdf. Accessed July 24, 2012.

The Emergency Evacuations Task Force peer-reviewed this paper. 